\title{
Implications of Work and Community Demands and Resources for Work-to-Family Conflict and Facilitation
}

\author{
Patricia Voydanoff \\ University of Dayton
}

\begin{abstract}
Based on a differential salience approach, this article examines the combined effects of work and community demands and resources on work-to-family conflict and facilitation. The study uses information from 2,507 employed respondents from the 1995 National Survey of Midlife Development in the United States. The findings indicate that work demands are relatively strongly related to work-to-family conflict, whereas work resources are relatively more important in relation to work-to-family facilitation. Social incoherence and friend demands are positively related to work-to-family conflict, whereas sense of community and support from friends have positive effects on facilitation. Community resources also show weak amplifying effects on some of the positive relationships between work resources and work-to-family facilitation. The findings provide modest support for the hypotheses.
\end{abstract}

The work-family interface consists of relationships between characteristics in the work (family) domain and activities, attitudes, and interpersonal relationships in the family (work) domain. Workfamily conflict and facilitation are linking mechanisms in the processes through which work and family characteristics are related to individual, family, and work well-being (Voydanoff, 2002). They are cognitive appraisals of the effects of the work (family) domain on the family (work) domain. According to Lazarus and Folkman (1984), cognitive appraisal is the process of deciding whether an experience is positive, stressful, or irrelevant with regard to wellbeing. A stressful appraisal occurs when individuals perceive that the demands of the environment exceed their resources, thereby endangering their well-being. Thus, the perception of work-family conflict or facilitation derives from assessing the relative resources and demands associated with work and family roles. Demands are structural or psychological claims associated with role requirements, expectations, and norms to which individuals must respond or adapt by exerting physical or mental effort. Resources are structural or psychological assets that may be used to facilitate performance, reduce demands, or generate additional resources.

Work-family conflict is a form of interrole conflict in which the demands of work and family roles are

Correspondence concerning this article should be addressed to Patricia Voydanoff, The Raymond L. Fitz, S. M. Center for Leadership in Community, University of Dayton, Dayton, OH 45469-1445. E-mail: Patricia.Voydanoff@notes.udayton.edu incompatible in some respect so that participation in one role is more difficult because of participation in the other role (Greenhaus \& Beutell, 1985). This conflict can take two forms: work-to-family conflict in which the demands of work make it difficult to perform family responsibilities and family-to-work conflict in which family demands limit the performance of work duties. Work-family facilitation is a form of synergy in which resources associated with one role enhance or make easier participation in the other role. It also can operate from either work to family or family to work. (See Wayne, Grzywacz, Carlson, \& Kacmar, 2003, for a review.) Work-tofamily conflict and work-to-family facilitation are either uncorrelated (Bakker \& Geurts, 2004; Sumer $\&$ Knight, 2001) or show weak negative relationships to each other (Colton, Hammer, \& Neal, 2002; Tiedje et al., 1990; Voydanoff, 2004b). A study of a subsample of employed respondents between the ages of 25 and 62 from the data set used in this article reported that work-to-family conflict and facilitation are not correlated and form separate factors in factor analyses (Grzywacz \& Marks, 2000). Thus, work-tofamily conflict and work-to-family facilitation are independent constructs rather than opposite ends of a single continuum.

Extensive research has examined relationships between various work demands and resources and work-to-family conflict. However, the conceptualization of work-family facilitation is less established than work-family conflict, and empirical research of its correlates is just beginning. Such conceptualization and research provides a much-needed corrective to the dominant emphasis on negative aspects of the 
work-family interface. Voydanoff (2004b) has proposed that work demands and resources have differential salience for conflict and facilitation such that work demands are related to work-to-family conflict, whereas work resources are associated with facilitation. The few studies that examine such a pattern of results provide empirical support (Bakker \& Geurts, 2004; Voydanoff, 2004b).

In the past few years, scholars and practitioners have begun to realize that it also is important to look beyond work and family characteristics to understand more fully the range of demands and resources that influence the ability of individuals and families to fulfill their work and family responsibilities. Demands and resources in the community always have influenced the work-family interface, for example, the availability of child care services in the community and the lack of fit between work hours and school hours. In addition, recent changes occurring in the work, community, and family domains are blurring the boundaries that differentiate one from another, for example the lack of geographic separation between paid work, community, and home and overlapping networks and obligations associated with work, community, and family life. Other structural changes have increased the difficulties experienced by working families such as the lengthening of work hours that is occurring for some at the same time that communities are becoming more limited in the services they are able to provide to working families. Therefore, understanding how work and community demands and resources combine to influence workto-family conflict and facilitation provides a necessary foundation for designing work and community policies and programs that reduce work-to-family conflict and increase work-to-family facilitation.

Research addressing such issues is in its infancy. Recently, a study of the parents of adolescents documented that parents' short work hours, low amounts of volunteer time in community and professional organizations, and moderate and high amounts of volunteer time in organized youth activities and informal helping were positively related to family wellbeing. Job and community satisfaction were positively associated with family well-being, whereas subjective job demands showed negative relationships (Voydanoff, 2004a, in press-b). Thus, demands and resources from both the work and community domains were associated with family well-being.

However, no known research has examined the effects of community demands and resources on the linking mechanisms between work and family, namely work-to-family conflict and facilitation. This article tests hypotheses based on a model that proposes that community demands and resources operate similarly to work demands and resources in relation to work-to-family conflict and facilitation, namely, that community demands are relatively salient for work-to-family conflict, whereas community resources are more strongly associated with work-tofamily facilitation. Thus, the model posits that both work and community demands are relatively strongly related to work-to-family conflict, whereas both work and community resources are relatively strongly associated with work-to-family facilitation. A comparable model is appropriate for family-to-work conflict and facilitation. However, the complexities involved in assessing the effects of demands and resources associated with multiple types of family relationships, for example, marital, parental, and extended kin, and the incomparability of subsample sizes with all employed respondents render such an analysis beyond the scope of this article. (See Voydanoff, in press-a, for such an analysis of family-to-work conflict and facilitation.)

The article has two purposes: first, to replicate the Voydanoff (2004b) study of the differential salience of work demands and resources for work-to-family conflict and facilitation, and second, to extend the model to incorporate community demands and resources as differentially salient sources of conflict and facilitation. The replication aspect of the study examines the differential salience of work demands and resources for conflict and facilitation by using data from a different national survey with a higher response rate and more reliable measures of core work demands and resources and work-to-family facilitation. The extension of the model to community demands and resources examines the extent to which community demands serve as independent sources of work-to-family conflict or exacerbate positive relationships between work demands and conflict. In addition, community resources are considered as independent sources of facilitation and as amplifiers of positive relationships between work resources and facilitation.

This article uses a differential salience approach as a framework for investigating the combined effects of work and community demands and resources on work-to-family conflict and facilitation. Work demands are either time-based or strain-based demands, whereas work resources include enabling resources and psychological rewards. Community demands focus on the psychological strain associated with demands from the generalized community, the neighborhood, and friends. Community resources include 
three types of social integration: sense of community, neighborhood attachment, and support from friends. The effects of these demands and resources on workto-family conflict and facilitation are examined for a large representative sample of employed individuals in the United States. The study examines the additive effects of work and community demands and resources on work-to-family conflict and facilitation and the moderating effects of community demands and resources on relationships between work demands and resources and work-to-family conflict and facilitation.

\section{Work and Community Demands and Work-to-Family Conflict and Facilitation}

Work and community demands and resources are expected to be differentially salient in relation to work-to-family conflict and facilitation. This differential salience approach proposes that work and community demands are positively related to work-tofamily conflict, whereas work and community resources are positively associated with work-to-family facilitation. One study has supported this approach for work demands and resources (Voydanoff, 2004b). A previous analysis using a subsample of employed respondents between 25 and 62 years old from the data set used in this article also found that relationships between some of the work demands and resources included here support the differential salience approach (Grzywacz \& Marks, 2000). However, the pattern of findings was not presented or interpreted in the context of a differential salience approach. This article replicates the Voydanoff study and extends its application to community demands and resources.

\section{Work Demands}

Work demands are expected to be relatively salient for work-to-family conflict because they are accompanied by processes that hinder the performance of family roles or deplete the resources needed for participation in family activities. However, these demands are likely to be less salient for work-to-family facilitation because facilitation is expected to result from resources that mobilize or engage individuals in family activities rather than from a lack of demands. This study examines two types of work demands: time-based and strain-based demands. Time-based demands such as long hours in paid work reduce the amount of time available for family activities, thereby making it difficult for employees to perform family duties and maintain family relationships. Previous research has revealed consistent positive relationships between paid work hours and work-to-family conflict, whereas work hours generally are unrelated to work-to-family facilitation (Clark, 2001; Colton et al., 2002; Frone, Yardley, \& Markel, 1997; Grzywacz \& Marks, 2000; Major, Klein, \& Ehrhart, 2002; Thompson, Beauvais, \& Lyness, 1999; Voydanoff, 2004b).

Job demands are a strain-based demand that can be expected to increase employees' negative emotions, stress, and fatigue. These reactions may spill over into family life through transmission processes in which work conditions are associated with psychological responses, which are then transferred into attitudes and behaviors at home. Negative transmission processes include negative emotional arousal, interpersonal withdrawal, energy depletion, and stress (Piotrkowski, 1979; Rothbard, 2001). This spillover may increase work-to-family conflict by limiting employees' ability to meet family responsibilities. Because spillover processes generally create similarities across domains (Edwards \& Rothbard, 2000), it is unlikely that job demands show strong negative relationships to work-to-family facilitation. Previous studies have shown that job demands are positively related to work-to-family conflict (Frone et al., 1997; Grzywacz \& Marks, 2000; Major et al., 2002; Parasuraman, Purohit, Godshalk, \& Beutell, 1996), whereas they show a positive association with work-to-family facilitation for men but not for women in one study (Grzywacz \& Marks, 2000). Previous research and the differential salience approach suggest the following hypothesis:

Hypothesis 1a: Work demands are more strongly positively related to work-to-family conflict than they are negatively related to workto-family facilitation.

\section{Community Demands}

Community demands and resources differ from work demands and resources in that they originate outside of the work and family domains. The extent to which they influence work-to-family conflict and facilitation depends on the permeability and flexibility of the boundaries among the three domains. Including community demands and resources in a test of the differential salience approach presumes enough permeability and flexibility that some carryover from community to the work-family interface 
exists. However, it is not expected that the community demands and resources will be as strongly related to work-to-family conflict and facilitation as work demands and resources are.

The community demands and resources included in the study draw from three aspects of community: the community as a whole, the neighborhood as a local geographic community, and friends who serve as a major source of primary group interaction outside the family. The community demands are strainbased demands that focus on negative perceptions of community life that may spill over to the workfamily interface such that they limit workers' ability to address work demands without experiencing workto-family conflict. As discussed above, this spillover may involve the transmission of negative emotions, stress, energy depletion, and interpersonal unavailability. Social incoherence, the opposite of social coherence as defined by Keyes (1998), extends beyond the local community to incorporate appraisals that society is not discernable, sensible, and predictable. Such perceptions and lack of grounding may operate as a stressor that influences work-to-family conflict. The perception of living in an unsafe neighborhood is another potential stressor that may carry over to the work-family interface by serving as a concern, distraction, or problem requiring concerted effort. High levels of personal and emotional demands from friends also may reduce the ability of workers to deal with the demands presented by their work, thereby increasing the likelihood of work-tofamily conflict. These demands may have less negative effects on work-to-family facilitation because they are not connected to the processes through which work and community resources create workto-family facilitation, namely enabling workers by generating useful resources or providing psychological rewards. No known studies have investigated such relationships. However, the differential salience approach suggests the following:

Hypothesis $1 b$ : Community demands are more strongly positively related to work-to-family conflict than they are negatively related to workto-family facilitation.

In addition to contributing to work-to-family conflict as independent stressors, community demands also may exacerbate the negative effects of work demands on conflict. It is possible that work demands are more strongly related to work-to-family conflict for those who experience high levels of community demands. Because so little is known in this area, both types of relationships are examined. This leads to the following:

Hypothesis 1c: Community demands exacerbate the positive relationships between work demands and work-to-family conflict.

\section{Work and Community Resources and Work-to-Family Facilitation and Conflict}

\section{Work Resources}

Contrary to work and community demands that are expected to be relatively strongly related to work-tofamily conflict, work and community resources are expected to be more strongly related to work-tofamily facilitation than conflict. Work and community resources include enabling resources and psychological rewards. Enabling resources in one domain may generate resources in another domain that provide the means for enhancing participation in the second domain. Enabling resources generally are associated with the structure or content of domain activities, for example, skills and abilities developed through domain activity and the availability of social support from others involved in the domain. Enabling resources contribute to work-family facilitation by increasing the competence and capabilities of individuals to perform across domains.

Job autonomy, an enabling resource that derives from the design of a job, refers to the extent to which employees are able to decide how to do their jobs. It is associated with resources such as time management skills, initiative, and self-confidence. When applied to family activities and relationships, it is expected to contribute to work-to-family facilitation. The extent to which enabling resources also reduce work-to-family conflict is unclear. Although job autonomy provides control on the job that reduces job stress, it may not carry over into family life such that it has a negative relationship to work-to-family conflict. Thus, autonomy is expected to be more salient for work-to-family facilitation than for work-to-family conflict. Previous studies have found that job autonomy is positively related to work-to-family facilitation (Demerouti \& Geurts, in press; Grzywacz \& Marks, 2000; Voydanoff, 2004b), whereas the findings for work-to-family conflict are mixed. Four studies revealed that job autonomy was not related to work-to-family conflict (Batt \& Valcour, 2003; Clark, 2001; Parasuraman et al., 1996; Voydanoff, 2004b); however, two others found a negative rela- 
tionship between autonomy and conflict (Grzywacz \& Marks, 2000; Maume \& Houston, 2001).

Psychological rewards, such as pride and respect, are an aspect of personality enrichment that increases self-esteem and gratification. These rewards may be transmitted into family life through positive psychological spillover processes. When the positive emotions, energy, and interpersonal availability associated with psychological rewards such as work pride are transferred into the family, they are expected to contribute to work-to-family facilitation. Because of the similarities generated across domains by psychological spillover, it is not expected that psychological rewards will show strong negative relationships to work-to-family conflict. No studies were located that examined these relationships. Despite limited and inconsistent research, the differential salience approach suggests the following:

Hypothesis 2a: Work resources are more strongly positively related to work-to-family facilitation than they are negatively related to work-to-family conflict.

\section{Community Resources}

The community resources included in the present study are aspects of social integration. Social integration generally is defined as structural or affective interconnectedness with others and with social institutions. It encompasses patterns of social interaction and participation and attitudes regarding institutions and relationships. Three types of social integration based on affective connections are considered: sense of community, neighborhood attachment, and support from friends. Sense of community has been defined by McMillan and Chavis (1986) as consisting of four interrelated elements: feeling of belonging, the sense that the individual and the group matter to each other, the feeling that members' needs will be met through group resources, and a shared history. Attitudinal neighborhood attachment is associated with neighborhood ties, trust, pride, and satisfaction (Woldoff, 2002). Support from friends is one type of informal social support, which may include resources such as emotional support, instrumental support, and support in the form of advice or information.

These three aspects of social integration are enabling resources that encompass social and psychological assets such as a sense of community belonging and support, a neighborhood that provides social order and support, and assistance and understanding from caring friends. These resources provide social embeddedness, social control and regulation, individual and group identity, interpersonal connections and attachment, access to other resources and support, and emotional sustenance. It is proposed that these resources facilitate the efforts of individuals and families to fulfill their work and family responsibilities so that work-to-family facilitation is increased. They provide additional enabling resources and support that combine with work resources to create work-tofamily facilitation. However, it is not clear whether community resources also may lower work-to-family conflict. The resources generated from social integration may reduce work-to-family conflict somewhat, but not to the extent that they increase work-tofamily facilitation. Previous research has not explored these community resources in relation to work-to-family facilitation or conflict. Nevertheless, the differential salience approach leads to the following hypothesis:

Hypothesis 2b: Community resources are more strongly positively related to work-to-family facilitation than they are negatively related to work-to-family conflict.

If community resources contribute to work-to-family facilitation independently of work resources, as stated above, they would serve as independent enhancing factors. In addition, community resources may amplify the positive effects of work resources on work-to-family facilitation. In this case, work resources would be more strongly related to work-tofamily facilitation for those with high levels of community resources. Because no research is available to establish the relative validity of these hypotheses, both are examined. This suggests the following hypothesis:

Hypothesis 2c: Community resources amplify positive relationships between work resources and work-to-family facilitation.

\section{Method}

\section{Data}

The data for the study are from the 1995 National Survey of Midlife Development in the United States (MIDUS), a nationally representative random-digit-dial sample of noninstitutionalized English-speaking adults, ages 25 to 74 , selected from working telephone banks in the coterminous United States. Respondents participated in a telephone interview with a response rate of $70 \%$ and a mail questionnaire with a response rate of $87 \%$, which yielded an overall rate of $61 \%$ for both parts of the survey. The subsample 
used in the analysis included the 2,667 respondents who were employed. When cases with missing data on any variable were omitted, the sample size was reduced to 2,507 .

\section{Measures}

Work-to-family conflict and facilitation. The measure of work-to-family conflict was the mean response to four items asking respondents how often in the past year they have experienced the following: "Your job reduces the effort you can give to activities at home," "Stress at work makes you irritable at home," "Your job makes you feel too tired to do the things that need attention at home," and "Job worries or problems distract you when you are at home." Responses ranged from $1=$ never to $5=$ all the time. Work-to-family facilitation was assessed by averaging responses to three items asking respondents how often in the past year they experienced the following: "The things you do at work help you deal with personal and practical issues at home," "The things you do at work make you a more interesting person at home," and "The skills you use on your job are useful for things you have to do at home" $(1=$ never to $5=$ all the time).

Work and community demands. The measure of paid work hours was the number of hours worked in an average week. Job demands were assessed by averaging responses to the following four questions: "How often do you have to work very intensively, that is, you are very busy trying to get things done?" "How often do different people or groups at work demand things from you that you think are hard to combine?" "How often do you have too many demands made on you?" and "How often do you have enough time to get everything done?" (reverse coded). Responses ranged from $1=$ never to $5=$ all the time.

The measure of social incoherence was the average response to two questions asking respondents how strongly they agree or disagree with the following: "The world is too complex for me" and "I cannot make sense of what's going on in the world" $(1=$ strongly disagree to $7=$ strongly agree). The measure, unsafe neighborhood, was the mean response to two questions asking respondents the extent to which they feel safe being out alone in their neighborhoods during the daytime or at night. Responses ranged from $1=$ a lot to $4=$ not at all. Friend demands was measured by averaging answers to the following four questions: "How often do your friends make too many demands on you?" "How often do they criticize you?" "How often do they let you down when you are counting on them?" and "How often do they get on your nerves?" $(1=$ never to $4=$ often $)$

Work and community resources. The measure of job autonomy was the mean response to the following four questions: "How often do you have a choice in deciding how you do your tasks at work?" "How often do you have a choice in deciding what tasks you do at work?" "How often do you have a say in decisions about your work?" and "How often do you have a say in planning your work environment-that is, how your workplace is arranged or how things are organized?" $(1=$ never to $5=$ all the time $)$. Work pride was assessed by averaging the level of agreement with the following two items: "When I think about the work I do on my job, I feel a good deal of pride" and "I feel that others respect the work I do on my job" $(1=$ not at all to $4=$ a lot).
Sense of community was the mean response to three questions asking respondents how strongly they agree with the following: "I don't feel I belong to anything I'd call a community" (reverse coded), "I feel close to other people in my community," and "My community is a source of comfort" $(1=$ strongly disagree to $7=$ strongly agree $)$. The measure of neighborhood attachment was the average of four items asking respondents how much the following describes their situation: "I could call on a neighbor for help if I needed it," "People in my neighborhood trust each other," "I feel very good about my home and my neighborhood," "My neighborhood is kept clean" $(1=$ not at all to $4=$ a lot). Support from friends was assessed by averaging responses to the following four questions: "How much do your friends really care about you?" "How much do they understand the way you feel about things?" "How much can you rely on them for help if you have a serious problem?" and "How much can you open up to them if you need to talk about your worries?" $(1=$ not at all to $4=$ a lot $)$.

Demographic characteristics. Gender was a dummy variable coded 1 for male. Age was coded in years. Race was a dummy variable coded 1 for non-White. Education was coded in 12 categories ranging from $1=$ no school or some grade school to $12=$ professional degree.

\section{Results}

Table 1 presents the means, standard deviations, zero-order correlations, and alpha coefficients of reliability for the variables in the analysis. The means for work-to-family conflict and facilitation indicate moderate levels of conflict and facilitation. With one exception, the means for the work and community demand scales are in the middle of their ranges. The mean for the unsafe neighborhood scale is relatively low. The means for the work and community resource scales reveal moderately high levels of these resources. Correlations among the predictors are low. The only correlation higher than .40 is between sense of community and neighborhood attachment $(r=$ .42). With one exception, the alpha coefficients of reliability are greater than .70 , ranging from .73 to .88. The alpha coefficient for the social incoherence scale is somewhat low at 65 .

The hypotheses are tested through hierarchical regression analysis. Tables 2 and 3 present the findings for work-to-family conflict and facilitation, respectively. Model 1 includes the demographic characteristics. Models 2 and 3 add the coefficients for work and community demands, which are followed by work and community resources in Models 4 and 5 and the interaction terms in Model 6.

Tests for the interaction effects predicted in Hypotheses $1 \mathrm{c}$ and $2 \mathrm{c}$ were conducted in two stages. First, regression analyses were performed that included demographic characteristics, work and community demands and resources, and the cross-product 


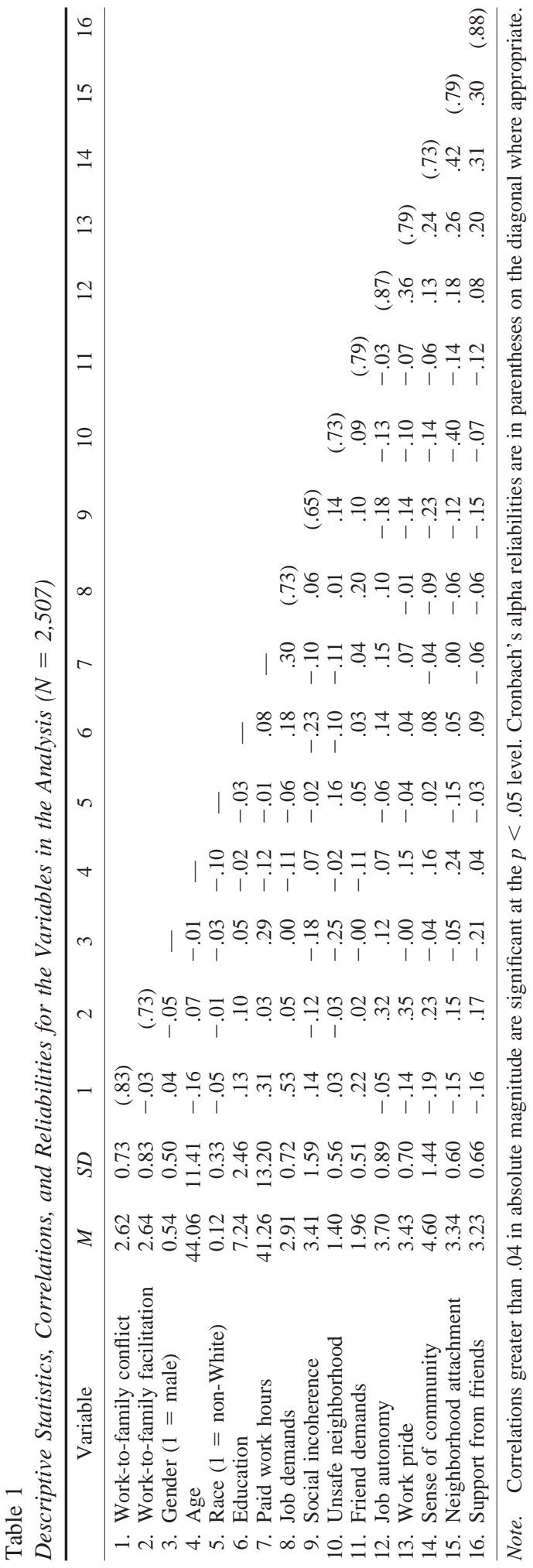

term of one work demand or resource and one community demand or resource. Mean centering was used for the variables included in the cross-product terms. Six equations were computed for work-tofamily conflict ( 2 work demands $\times 3$ community demands) and six for work-to-family facilitation (2 work resources $\times 3$ community resources). Interaction terms that were statistically significant in these equations were included in Model 6 of Tables 2 and 3. Graphing was used as a basis for interpretation; however, because of the weakness of the interactions, the graphs are not shown.

As predicted, Model 2 in Table 2 reveals that both work demands (work hours and job demands) show statistically significant positive relationships with work-to-family conflict. In addition, Model 2 in Table 3 shows that the positive relationships between job demands and work-to-family facilitation are relatively weak. However, the sign of the relationships between work demands and facilitation is opposite that predicted in Hypothesis 1a. The statistically significant positive relationship between paid work hours and work-to-family facilitation is eliminated when job resources are entered into the analysis. However, the weak positive relationship between job demands and facilitation is maintained across the models. Work demands explain $27 \%$ of the variance in work-to-family conflict versus $0.4 \%$ of the variance in work-to-family facilitation. Thus, Hypothesis 1a is supported for the differential salience of work demands in relation to conflict and facilitation.

Two of the three community demands (social incoherence and friend demands) show statistically significant positive relationships to work-to-family conflict (see Table 2, Model 3). Social incoherence also is negatively related to work-to-family facilitation (see Table 3, Model 3). However, this relationship decreases when work and community resources are added to the equation. Friend demands are positively related to facilitation, especially when work and community resources are included. Unsafe neighborhood is not significantly related to either conflict or facilitation. Community demands explain $3.3 \%$ of the variance in work-to-family conflict and $1.5 \%$ of the variance in facilitation. Hypothesis $1 \mathrm{~b}$ receives mixed support.

As expected, Model 4 in Table 3 reveals that job autonomy and work pride show strong positive associations with work-to-family facilitation. Table 2, Model 4, indicates relatively weak but statistically significant negative relationships between job autonomy and work pride and conflict. These job resources 
Table 2

Regressions of Work-to-Family Conflict on Demographic Characteristics, Work and Community Demands, and Work and Community Resources $(N=2,507)$

\begin{tabular}{|c|c|c|c|c|c|c|}
\hline Variable & Model 1 & Model 2 & Model 3 & Model 4 & Model 5 & Model 6 \\
\hline \multicolumn{7}{|l|}{ Demographic characteristics } \\
\hline Gender $(1=$ male $)$ & .03 & -.02 & .01 & .01 & -.02 & -.02 \\
\hline Age & $-.16^{* * *}$ & $-.09 * * *$ & $-.09 * * *$ & $-.07 * * *$ & $-.06 * *$ & $-.06 * * *$ \\
\hline Race (1 = non-White) & $-.07 * *$ & $-.03 \dagger$ & $-.04 *$ & $-.04 *$ & $-.04 *$ & $-.04 *$ \\
\hline Education & $.12 * * *$ & $.03 \dagger$ & $.07 * * *$ & $.08 * * *$ & $.08 * * *$ & $.08 * * *$ \\
\hline \multicolumn{7}{|l|}{ Work demands } \\
\hline Paid work hours & & $.16^{* * *}$ & $.17 * * *$ & $.19 * * *$ & $.19 * * *$ & $.18^{* * * *}$ \\
\hline Job demands & & $.47 * * *$ & $.43^{* * * *}$ & $.43 * * *$ & $.43 * * *$ & $.43 * * *$ \\
\hline \multicolumn{7}{|l|}{ Community demands } \\
\hline Social incoherence & & & $.14 * * *$ & $.12 * * *$ & $.10 * * *$ & $.10 * * *$ \\
\hline Unsafe neighborhood & & & .03 & .02 & -.00 & -.01 \\
\hline Friend demands & & & $.10 * * *$ & $.10 * * *$ & $.09 * * *$ & $.09 * * *$ \\
\hline \multicolumn{7}{|l|}{ Work resources } \\
\hline Job autonomy & & & & $-.07 * * *$ & $-.07 * * *$ & $-.07 * * *$ \\
\hline Work pride & & & & $-.08 * * *$ & $-.06 * *$ & $-.06^{* * *}$ \\
\hline \multicolumn{7}{|l|}{ Community resources } \\
\hline Sense of community & & & & & $-.07 * * *$ & $-.07 * * *$ \\
\hline Neighborhood attachmen & & & & & -.03 & -.02 \\
\hline Support from friends & & & & & $-.06 * * *$ & $-.06 * *$ \\
\hline \multicolumn{7}{|l|}{ Interactions } \\
\hline \multicolumn{7}{|l|}{ Job Demands $\times$ Unsafe } \\
\hline Neighborhood & & & & & & $.04 *$ \\
\hline \multicolumn{7}{|l|}{ Job Demands $\times$ Friend } \\
\hline Demands & & & & & & .03 \\
\hline \multicolumn{7}{|l|}{$\begin{array}{l}\text { Job Autonomy } \times \text { Sense of } \\
\text { Community }\end{array}$} \\
\hline \multicolumn{7}{|c|}{ Job Autonomy $\times$ Support From } \\
\hline Friends & & & & & & \\
\hline \multicolumn{6}{|l|}{ Work Pride $\times$ Sense of } & Community \\
\hline \multicolumn{7}{|c|}{ Work Pride $\times$ Support From } \\
\hline \multicolumn{7}{|l|}{ Friends } \\
\hline$R^{2}$ & .046 & .316 & .349 & .364 & .374 & .377 \\
\hline Change in $R^{2}$ & .046 & .270 & .033 & .015 & .010 & .002 \\
\hline$F$ for change in $R^{2}$ & $30.14 * * *$ & $493.77 * * *$ & $42.31 * * *$ & $29.66 * * *$ & $13.91 * * *$ & $4.12 *$ \\
\hline
\end{tabular}

Note. Standardized regression coefficients are presented.

$\dagger p<.10 . \quad * p<.05 . \quad * * p<.01 . \quad * * * p<.001$ (two-tailed tests).

explain $14.2 \%$ of the variance in work-to-family facilitation and $1.5 \%$ of the variance in conflict. Thus, Hypothesis $2 \mathrm{a}$ is supported.

Two of the community resources (sense of community and support from friends) show statistically significant positive relationships to work-to-family facilitation and negative relationships to work-tofamily conflict. However, neighborhood attachment is not related to either conflict or facilitation (see Model 5 in Tables 2 and 3). Community resources explain $2 \%$ of the variance in facilitation and $1 \%$ of the variance in conflict. Hypothesis $2 \mathrm{~b}$ receives limited support.

Model 6 in Table 2 indicates that community de- mands have limited exacerbating effects on relationships between work demands and work-to-family conflict. In the separate equations for each of the interaction terms, none of the three interactions that include paid work hours was statistically significant, whereas two of the three terms including job demands were significant. When these two statistically significant interactions are entered together in the final equation, one remains statistically significant, whereas the other approaches statistical significance. The positive relationship between job demands and work-to-family conflict is slightly stronger for those living in an unsafe neighborhood. However, the practical significance of the interactions is limited by the 
Table 3

Regressions of Work-to-Family Facilitation on Demographic Characteristics, Work and Community Demands, and Work and Community Resources $(N=2,507)$

\begin{tabular}{|c|c|c|c|c|c|c|}
\hline Variable & Model 1 & Model 2 & Model 3 & Model 4 & Model 5 & Model 6 \\
\hline \multicolumn{7}{|l|}{ Demographic characteristics } \\
\hline Gender $(1=$ male $)$ & $-.06^{* *}$ & $-.07 * *$ & $-.10 * * *$ & $-.09 * * *$ & $-.06 * *$ & $-.06^{* *}$ \\
\hline Age & $.07 * *$ & $.08 * * *$ & $.09 * * *$ & .03 & .01 & .01 \\
\hline Race $(1=$ non-White $)$ & .00 & .00 & .00 & .02 & .01 & .01 \\
\hline Education & $.11 * * *$ & $.10 * * *$ & $.07 * *$ & $.05^{*}$ & $.04 *$ & $.04 \dagger$ \\
\hline \multicolumn{7}{|l|}{ Work demands } \\
\hline Paid work hours & & $.05^{*}$ & $.04 \dagger$ & -.01 & -.00 & -.01 \\
\hline Job demands & & .03 & $.04 *$ & .03 & $.04 \dagger$ & $.04 *$ \\
\hline \multicolumn{7}{|l|}{ Community demands } \\
\hline Social incoherence & & & $-.12 * * *$ & $-.06 * *$ & -.02 & -.02 \\
\hline Unsafe neighborhood & & & -.03 & .01 & .02 & .02 \\
\hline Friend demands & & & .03 & $.05^{*}$ & $.05 * *$ & $.05^{* *}$ \\
\hline \multicolumn{7}{|l|}{ Work resources } \\
\hline Job autonomy & & & & $.22 * * *$ & $.22 * * *$ & $.22 * * *$ \\
\hline Work pride & & & & $.26 * * *$ & $.23 * *$ & $.24 * * *$ \\
\hline \multicolumn{7}{|l|}{ Community resources } \\
\hline Sense of community & & & & & $.14 * * *$ & $.13 * * *$ \\
\hline Neighborhood attachment & & & & & -.02 & -.01 \\
\hline Support from friends & & & & & $.06^{* *}$ & $.06^{* *}$ \\
\hline \multicolumn{7}{|l|}{ Interactions } \\
\hline \multicolumn{7}{|l|}{ Job Demands $\times$ Unsafe Neighborhood } \\
\hline Job Demands $\times$ Friend Demands & & & & & & \\
\hline Job Autonomy $\times$ Sense of Community & & & & & & -.00 \\
\hline Job Autonomy $\times$ Support From Friends & & & & & & $.04 \dagger$ \\
\hline Work Pride $\times$ Sense of Community & & & & & & $.05^{*}$ \\
\hline Work Pride $\times$ Support From Friends & & & & & & .01 \\
\hline$R^{2}$ & .019 & .022 & .037 & .180 & .200 & .204 \\
\hline Change in $R^{2}$ & .019 & .004 & .015 & .142 & .020 & .005 \\
\hline$F$ for change in $R^{2}$ & $11.92 * * *$ & $4.82 * *$ & $12.99 * * *$ & $216.11 * * *$ & $20.93 * * *$ & $3.68 * *$ \\
\hline
\end{tabular}

Note. Standardized regression coefficients are presented.

$\dagger p<.10$. * * $p<.05$. *** $p<.01$. *** $p<.001$ (two-tailed tests).

extremely low percentage of variance explained in Model 6-0.2\%.

Support for community resources as amplifiers of positive relationships between work resources and work-to-family facilitation is stronger. Four of the six interaction terms showed statistically significant amplifying effects in the separate equations for each interaction term. When these interaction terms are included in Model 6 of Table 3, two remain statistically significant. Support from friends amplifies the positive relationship between job autonomy and work-to-family facilitation, whereas a sense of community amplifies the relationship between work pride and facilitation. Thus, in some situations, work resources are more strongly related to facilitation for those who also have community resources. However, the combined effects of these interactions only explain $0.5 \%$ of the variance in work-to-family facilitation, thereby limiting the practical significance of the amplifying effects.

\section{Discussion}

This article examined the relative salience of work and community demands and resources in relation to work-to-family conflict and facilitation. As expected, the differential salience approach receives stronger support for work demands and resources than for community demands and resources. The findings for the differential salience of work demands and resources for conflict and facilitation replicate findings reported by Voydanoff (2004b). In addition, the differential salience approach receives modest support for the effects of community demands and resources on conflict and facilitation.

The findings generally support the differential salience approach for work demands and resources. Work demands are relatively more important than resources in relation to work-to-family conflict, whereas work resources are relatively more important than demands in relation to facilitation. How- 
ever, the finding that work resources show statistically significant negative relationships to work-tofamily conflict suggests that work resources also play a part in reducing work-to-family conflict. Work demands do not show negative relationships to workto-family facilitation. However, the modest positive relationship between job demands and facilitation suggests that job demands may reflect a high level of work engagement that makes a minor positive contribution to facilitation in addition to its strong relationship to conflict. The pattern of results supports Voydanoff (2004b), who reported that work demands (paid work hours, extra work without notice, job insecurity, and time pressure) were the major contributors to work-to-family conflict, whereas work resources (autonomy, learning opportunities, respect, and meaningful work) were the most important sources of facilitation. However, three work resources also showed modest negative relationships to conflict, whereas one work demand, time pressure, was negatively associated with facilitation. This study extends the Voydanoff study by incorporating several improved measures, namely the single-item measure of time pressure is expanded to a scale of job demands, the single-item indicators of psychological rewards are replaced by a scale of work pride, and the measure of work-to-family facilitation has a reliability of .73 compared with .53 for the earlier study. The measures of work-to-family facilitation also focus on different aspects: energy and mood in the earlier study versus activities and skills in the present study.

The differential salience approach for the effects of community resources on work-to-family conflict and facilitation also receives some support. Two community demands, social incoherence and friend demands, are more strongly related to conflict than facilitation, whereas an unsafe neighborhood is not related to either conflict or facilitation. However, as with job demands, friend demands show positive rather than negative relationships to facilitation. Two of the three community resources, sense of community and support from friends, are negatively related to conflict and positively related to facilitation, whereas the third, neighborhood attachment, is unrelated to both conflict and facilitation. Thus, sense of community and support from friends serve as independent compensating factors in relation to conflict and independent enhancing factors in relation to facilitation. It is not clear why community and friend variables show consistent relationships with conflict and facilitation while neighborhood factors do not. Communities, neighborhoods, and friends seem to provide comparable demands and resources that help or hinder individuals and families fulfill their work and family responsibilities. One possible explanation is that the measure of an unsafe neighborhood is a very limited indicator of neighborhood demands, whereas neighborhood attachment is less focused than the other measures. It incorporates relatively diverse resources associated with neighborhoods, including help, trust, cleanliness, and satisfaction.

The findings of this study are merely suggestive with regard to the moderating effects of community demands and resources. Support for exacerbating effects is very weak and limited to the effects of an unsafe neighborhood on the relationship between job demands and work-to-family conflict. The two statistically significant amplifying effects of community resources on relationships between work resources and work-to-family facilitation provide stronger support for the possibility of interactive effects of work and community factors on conflict and facilitation. However, none of the interactions explain even $1 \%$ of the variance in conflict or facilitation. Further research is needed to determine the extent to which such effects occur.

Research that examines community factors in relation to the work-family interface is just beginning. This study has focused on three strain-based demands associated with social integration: social incoherence, an unsafe neighborhood, and friend demands. However, it also is important to study time-based demands such as the level of participation in community organizations and informal community activities. Community resources other than those associated with social integration also may be important, for example, the extent to which communities provide formal programs and services needed by working families, the amount and types of informal community supports provided to working families, the availability of transportation to and from work, and a physical layout that makes it easy or difficult to access needed services. Additional studies are needed to explore the influence of these community demands and resources on work-family conflict and facilitation.

This article argues that we need to look beyond work characteristics to broaden our understanding of the range of demands and resources that are associated with work-to-family conflict and facilitation. It also suggests that work and community demands and resources operate together in additive and interactive ways to influence work-family integration. The independent stressor and enhancing effects reveal that community demands and resources influence workto-family conflict and facilitation for all employees 
regardless of the level of their work demands or resources. However, these effects are modest. If future research documents exacerbating effects of community demands on relationships between work demands and work-to-family conflict, it would indicate that community demands increase the level of conflict for those experiencing work demands. The very limited amplifying effects found in this study suggest that community resources may further increase the level of facilitation for those with work resources. Despite its limitations, this study takes an important step in formulating and testing how community demands and resources combine with work demands and resources to influence work-to-family conflict and facilitation. Such knowledge is needed for the formulation of work and community-based policies designed to reduce conflict and increase facilitation.

\section{References}

Bakker, A. B., \& Geurts, S. A. E. (2004). Towards a dual-process model of work-home interference. Work and Occupations, 31, 345-366.

Batt, R., \& Valcour, P. M. (2003). Human resource practices as predictors of work-family outcomes and employee turnover. Industrial Relations, 42, 189-220.

Clark, S. C. (2001). Work cultures and work/family balance. Journal of Vocational Behavior, 58, 348-365.

Colton, C. L., Hammer, L. B., \& Neal, M. G. (2002, April). Informal organizational support and work and family outcomes. Paper presented at the annual meeting of the Society of Industrial and Organizational Psychology, Toronto, Ontario, Canada.

Demerouti, E., \& Geurts, S. (in press). Towards a typology of work-home interaction. Community, Work \& Family.

Edwards, J. R., \& Rothbard, N. P. (2000). Mechanisms linking work and family. Academy of Management Review, 25, 178-199.

Frone, M. R., Yardley, J. K., \& Markel, K. S. (1997). Developing and testing an integrative model of the workfamily interface. Journal of Vocational Behavior, 50, $145-167$.

Greenhaus, J. H., \& Beutell, N. J. (1985). Sources of conflict between work and family roles. Academy of Management Journal, 10, 76-88.

Grzywacz, J. G., \& Marks, N. F. (2000). Reconceptualizing the work-family interface. Journal of Occupational Health Psychology, 5, 111-126.

Keyes, C. L. (1998). Social well-being. Social Psychology Quarterly, 61, 121-140.

Lazarus, R. S., \& Folkman, S. (1984). Stress, appraisal, and coping. New York: Springer.
Major, V. S., Klein, K. J., \& Ehrhart, M. G. (2002). Work time, work interference with family, and psychological distress. Journal of Applied Psychology, 87, 427-436.

Maume, D. J., \& Houston, P. (2001). Job segregation and gender differences in work-family spillover among white-collar workers. Journal of Family and Economic Issues, 22, 171-189.

McMillan, D. W., \& Chavis, D. M. (1986). Sense of community: A definition and theory. Journal of Community Psychology, 14, 6-23.

Parasuraman, S., Purohit, Y. S., Godshalk, V. M., \& Beutell, N. J. (1996). Work and family variables, entrepreneurial career success, and psychological well-being. Journal of Vocational Behavior, 48, 275-300.

Piotrkowski, C. (1979). Work and the family system. New York: Free Press.

Rothbard, N. P. (2001). Enriching or depleting? The dynamics of engagement in work and family roles. Administrative Science Quarterly, 46, 655-684.

Sumer, H. C., \& Knight, P. A. (2001). How do people with different attachment styles balance work and family? Journal of Applied Psychology, 86, 653-663.

Thompson, C. A., Beauvais, L. L., \& Lyness, K. S. (1999). When work-family benefits are not enough. Journal of Vocational Behavior, 54, 392-415.

Tiedje, L. B., Wortman, C. B., Downey, G., Emmons, C., Biernat, M., \& Lang, E. (1990). Women with multiple roles. Journal of Marriage and the Family, 52, 63-72.

Voydanoff, P. (2002). Linkages between the work-family interface and work, family, and individual outcomes. Journal of Family Issues, 23, 138-164.

Voydanoff, P. (2004a). The effects of work and community resources and demands on family integration. Journal of Family and Economic Issues, 25, 7-23.

Voydanoff, P. (2004b). The effects of work demands and resources on work-to-family conflict and facilitation. Journal of Marriage and Family, 66, 398-412.

Voydanoff, P. (in press-a). The differential salience of family and community demands and resources for family-towork conflict and facilitation. Journal of Family and Economic Issues.

Voydanoff, P. (in press-b). Implications of work and community resources and demands for marital quality. Community, Work, \& Family.

Wayne, J. H., Grzywacz, J. G., Carlson, D. S., \& Kacmar, M. K. (2003). Work-family facilitation: A theoretical elaboration of the construct. Manuscript submitted for publication.

Woldoff, R. A. (2002). The effects of local stressors on neighborhood attachment. Social Forces, 31, 87-116.

Received August 14, 2003

Revision received December 8, 2003

Accepted January 6, 2004 